\title{
Одночастотный тулиевый лазер с широкополосным самосканированием частоты
}

\author{
А.Е. Бударных ${ }^{1,2}$, А.Д. Владимирская ${ }^{1,3}, \underline{\text { И.А. Лобач }}^{1,2, *}$, С.И. Каблуков ${ }^{1,2}$ \\ ${ }^{1}$ Институт автоматики и электрометрии СО РАН \\ ${ }^{2}$ Новосибирский государственный университет \\ ${ }^{3}$ Новосибирский государственный технический университет \\ *E-mail: lobach@iae.nsk.su
}

DOI:10.31868/RFL2018.57-58

Лазеры с самоиндуцированным сканированием (или для простоты - c самосканированием) частоты генерации являются наиболее простым вариантом перестирываемых лазерных источников [1], которым не требуется специальных элементов для перестройки и электрических драйверов. В основе работы самосканирующих лазеров является формирование динамических решеток показателя преломления и усиления в активной среде лазера [2]. Динамика спектра напрямую связана с динамикой интенсивности лазера - длина волны генерации меняется скачкообразно от импульса к импульсу на величину кратную частоте межмодовых биений резонатора. В то же время существуют схемы резонатора лазера [2], в которых реализуется режим одночастотного сканирования, когда каждый импульс состоит из одной продольной моды с шириной 1 МГц. На данный момент самоиндуцированное сканирование уже продемонстрировано в разных спектральных диапазонах от 1 [1] до 2.1 мкм [3-4]. В случае реализации перестраиваемой генерации в области 2 мкм перспективно использование лазеров для диагностики поглощения парами воды и углекислого газа при анализе состояния атмосферы. Простота конструкции самосканирующих лазеров позволяет составить конкуренцию классическим перестраиваемым лазерам в ряде приложений (например, см. [5]), и можно ожидать аналогичной замены для лазеров с перестройкой в области 2 мкм. Однако, характеристики продемонстрированных ранее гольмиевых [3] и тулий-гольмиевых [4] лазеров с самосканированием частоты пока далеки от требуемых для практических приложений по причине неустойчивости режима сканирования [3] или нелинейного характера перестройки [4]. В данной работе был продемонстрирован самосканирующий тулиевый лазер с линейной поляризацией излучения и с рекордным диапазоном сканирования превышающим 22 нм в области 1.92 мкм. Главная особенность лазера заключается в генерации регулярных импульсов, каждый из которых состоит из одной продольной моды. Постоянный скачок частоты между импульсами $\sim 8$ МГц совместно с регулярной динамикой интенсивности обеспечивают высокую линейность перестройки частоты.
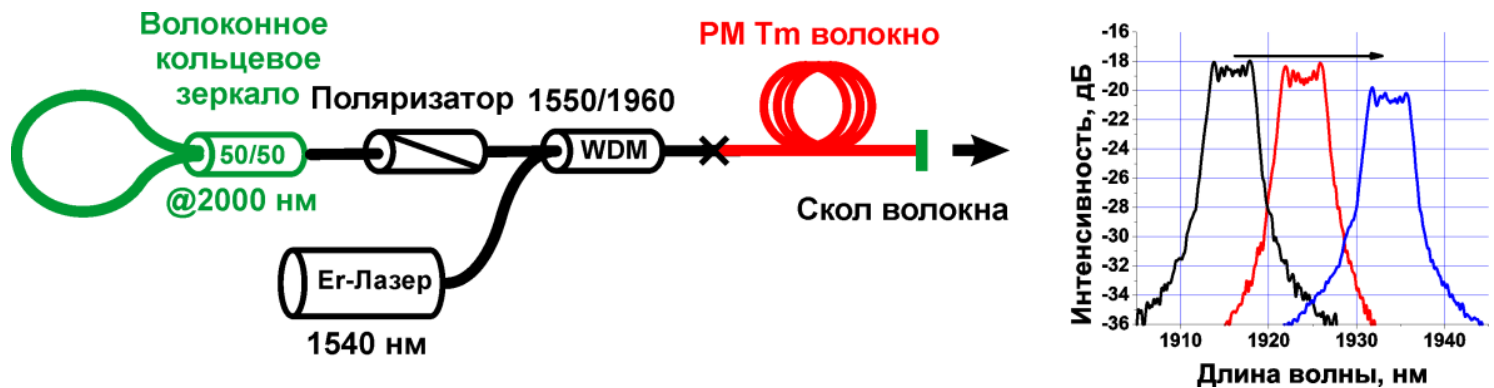

Рис. 1. Схема тулиевого лазера с самосканированием частоты и выходной спектр генерации, измеренный в различные моменты времени. 
Схема тулиевого лазера с линейной поляризацией излучения и с самосканированием частоты представлена на Рис.1. Активное волокно с сохранением поляризации, легированное тулием (5 метров PM-TSF-9/125 Nufern) нака-чивалась через спектрально-селективный разветвитель 1550/1960 WDM эрбиевым волоконным лазером с длиной волны генерации 1540 нм и максимальной выходной мощностью $\sim 1.5$ Вт. Резонатор тулиевого лазера был сформирован плотным кольцевым зеркалом и торцом сколотого под прямым углом волокна с отражением Френеля $\sim 3 \%$. Для получения одного поляризационного состояния излучения все компоненты лазеры были выполнены из волокна с сохранением поляризации, а в схему добавлен волоконный поляризатор. Лазерная генерация начинались при мощности накачки выше 300 мВт с дифференциальной эффективностью $44 \%$. Режим самосканирования частоты в области 1.92 мкм (Рис. 1 и 2а) можно было наблюдать на оптическом анализаторе спектра (OSA203C, Thorlabs) вплоть до мощности накачки 1.3 Вт. Характерная динамика центра линии генерации представлена на Рис.2а. Можно заметить, что диапазон сканирования превышает $21 \mathrm{нм}$, а скорость сканирования достигает $10 \mathrm{Hм} /$ сек. Более детальное измерение диапазона сканирования было произведено с помощью волоконного интерферометра Маха-Цендера. Было установлено, что область сканирования увеличивается с ростом выходной мощности и может достигать 24 нм (Рис.2б). Динамика интенсивности состоит из регулярных микросекундных импульсов, а в радиочастотном спектре сигнала наблюдаются биения только на одной межмодовой частоте, возникающие в процессе генерации нового импульса самосканирующего лазера. Последние два результата свидетельствуют об одночастотности режима самосканирования частоты [2].
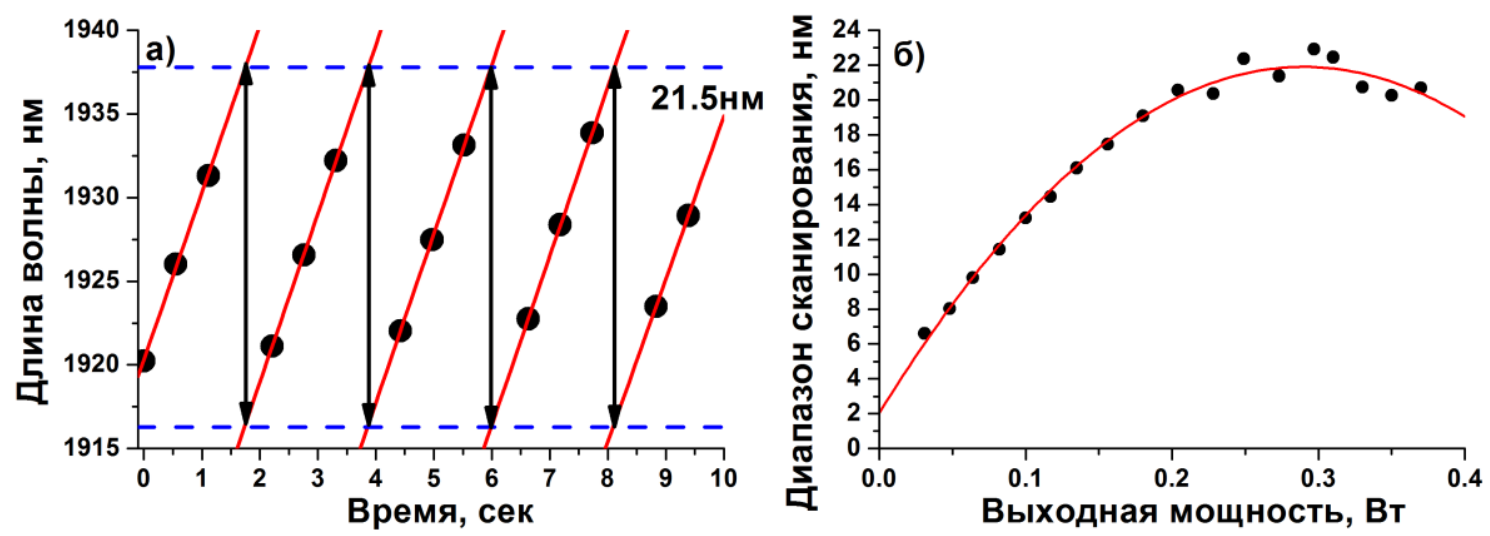

Рис. 2. (а) Характерная динамика длины волны. (б) Зависимость диапазона сканирования от выходной мощности и генерации.

Более детальное описание экспериментов по характеризации излучения реализованного источника, а также по демонстрации практического применения при регистрации спектра поглощения воды в атмосфере будет представлено в докладе.

Работа выполнена при финансовой поддержке РНФ (грант 18-12-00243).

\section{Литература}

[1] I.A. Lobach et al, Opt. Express, 19, 17632 (2011)

[2] I.A. Lobach et al, Laser Phys. Lett., 11, 045103 (2014)

[3] P. Navratil et al, Opto-Electronics Review, 26, 29 (2018).

[4] X. Wang et al, Opt. Express 21, 16290 (2013).

[5] A.Yu. Tkachenko et al, Opt. Express 25, 17600 (2017) 